This item was submitted to Loughborough's Research Repository by the author.

Items in Figshare are protected by copyright, with all rights reserved, unless otherwise indicated.

\title{
Seasonal impact-based mapping of compound hazards
}

PLEASE CITE THE PUBLISHED VERSION

https://doi.org/10.1088/1748-9326/abbc3d

PUBLISHER

IOP Publishing Ltd

VERSION

VoR (Version of Record)

\section{PUBLISHER STATEMENT}

This is an Open Access Article. It is published by IOP under the Creative Commons Attribution 4.0 International Licence (CC BY 4.0). Full details of this licence are available at: https://creativecommons.org/licenses/by/4.0/

\section{LICENCE}

CC BY 4.0

\section{REPOSITORY RECORD}

Hillier, John, and Richard S Dixon. 2020. "Seasonal Impact-based Mapping of Compound Hazards". Loughborough University. https://hdl.handle.net/2134/13050083.v1. 
LETTER • OPEN ACCESS

\section{Seasonal impact-based mapping of compound hazards}

To cite this article: J K Hillier and R S Dixon 2020 Environ. Res. Lett. 15114013

View the article online for updates and enhancements. 


\section{Environmental Research Letters}

\section{LETTER}

\section{Seasonal impact-based mapping of compound hazards}

\section{OPEN ACCESS}

RECEIVED

15 June 2020

REVISED

2 September 2020

ACCEPTED FOR PUBLICATION

28 September 2020

PUBLISHED

15 October 2020

Original content from this work may be used under the terms of the Creative Commons Attribution 4.0 licence.

Any further distribution of this work must maintain attribution to

the author(s) and the title

of the work, journal citation and DOI.

\author{
J K Hillier ${ }^{1}$ and R S Dixon \\ 1 Geography, Loughborough University, LE11 3TU, United Kingdom \\ 2 Department of Meteorology, University of Reading, RG6 6BG, United Kingdom \\ E-mail: j.hillier@lboro.ac.uk
}

Keywords: compound hazard, precipitation, extreme wind, extratropical cyclone, storm, flooding

Supplementary material for this article is available online

\section{Introduction}

Considering hazards in isolation may both overand under-estimate risk [1-4], and 'compound risk' is emerging as a term to encompass research to identify and understand the impact of combined hazards [5]. Over meteorological timescales (hours to weeks), even the joint behaviours of hazards whose origin involves notably different physical processes (e.g. damaging wind, extreme cold or heat, fluvial flooding, storm surge) is widely studied [6-12]. Over climatological timescales (seasonal to annual), often invoking a climate mode such as the North Atlantic Oscillation (NAO), there are multi-hazard reviews [13], but a focus has been on individual hazards [14-17] or pairwise extremes of a single variable such as temperature (hot/cold) or precipitation (wet/dry) [18, 19]. Links between potentially timelagged events of different hazard types via persistent underlying environmental conditions $[2,20]$ are less studied, especially when also adopting an impactcentric approach. Using the hazards of flooding and extreme wind in Europe as an example, we illustrate that impact-based mapping can identify scientifically interesting phenomena whilst using metrics (proxies) related to aggregated risk over a planning timescale that are of interest to infrastructure operators, government agencies, and (re)insurance.
Inland flooding and extreme wind are two of Europe's most impactful hazards [21]. They are commonly assessed separately [14, 22, 23] although, at meteorological timescales, case studies of strong storms (low-pressure systems, extratropical cyclones) show both classes of damage can co-occur during the same weather system [24-28]. Intriguingly, when only short timescales $(<72 \mathrm{~h})$ are used to map correlation in the extremes of precipitation and wind across Europe [12], the dependency is weak in Great Britain (GB). In contrast, a substantive correlation for the $\mathrm{GB}$ is proposed to exist $\left(r_{p} \approx 0.4-0.7\right.$, $p<0.05)$ in longer time windows of weeks up to a year $[2,4,11,29]$. A way to reconcile these observations is the proposal of Hillier et al [2] that compound risk is elevated by a systematic, multi-storm relationship on timescales up to seasonal (hours to months), driven by persistent underlying environmental conditions. It has not yet been possible to fully assess this idea as the GB estimates represent a single national figure $[2,11]$, short time-series of about 15 years $[2,4]$, or are from climatic variables that are not established to be metrics relating to impact (e.g. $[29,30])$. Thus, to overcome these limitations, we advocate using seasonal-scale and impactbased proxies for hazard to map where flooding and extreme winds do or do not compound across Europe. 


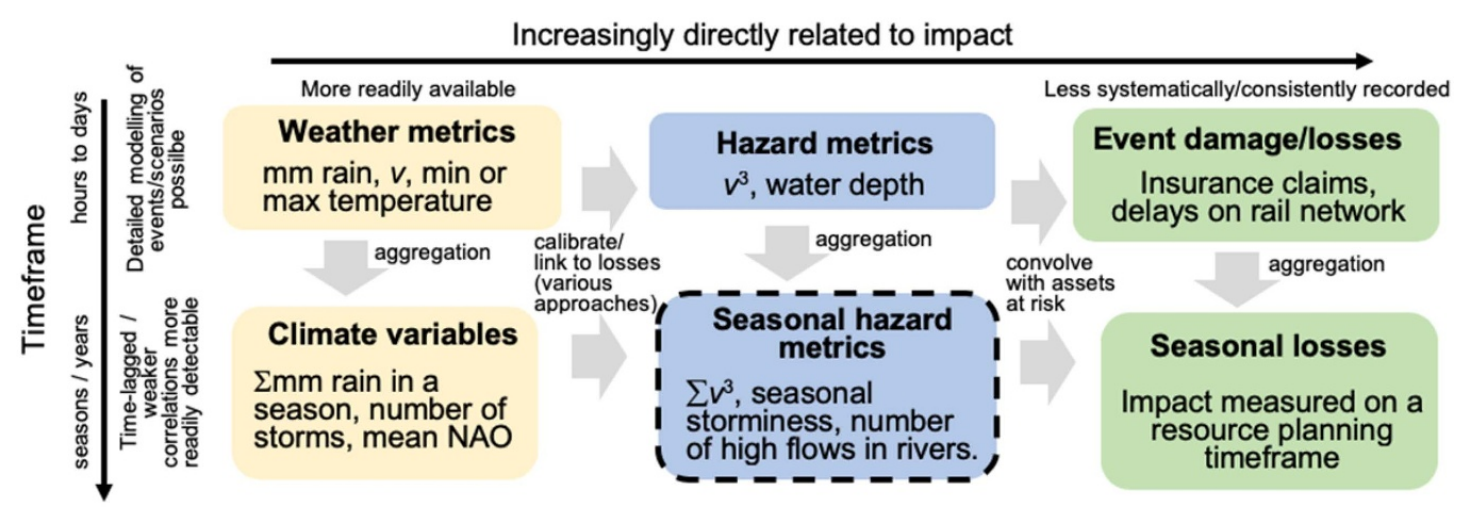

Figure 1. Two-dimensional typology of proxies for the impact of natural hazards. On the $x$-axis, variation is in how directly proxies are related to impact, ranging from meteorological (weather/climate) variables to quantifications of particular classes of damage such as insurance losses. Proxies may cover short or long durations, depicted on the $y$-axis. The blue box with a dashed outline highlights the seasonal-scale, impact-based hazard metrics that are advocated here as useful proxies for work on compound hazards.

\section{Method \& data}

\subsection{Selection of metrics for correlation}

In the context of natural hazards, risk is the possibility of an adverse consequence, so investigations of compound risk select proxies for impact $[2,29,31,32]$. Types of potentially useful impact proxy can be distinguished by how directly they relate to experienced impacts, and by the timeframe they represent (figure 1). Here, the hypothesis is that the hazards of flooding and extreme wind are linked by persistent underlying environmental conditions $[2,4]$, so hazard metrics at a seasonal (climatic) timescale are selected as proxies for impact (figure 1-blue box with a dashed outline). Over a season stochastic, sporadically occurring and relatively uncommon extremes accumulate, permitting any coherent 'signal' of correlation to be detected most readily. By using this timeframe, any sub-seasonal time-lags between events are implicitly accounted for; lags of up to 14 days are known and thought to arise from storm sequences [11], but other time spans and physical mechanisms may also exist.

In the typology of figure 1 hazard metrics are proxies for impact, which are based on weather/climate metrics; without risk of an impact, there is no hazard. There may be intermediate modelling (e.g. hydrological, hydraulic) but the crucial factor is that the metric, such as flood water depth, can be linked to eventual impact. This study uses hazard metrics derived by explicit and quantitative calibration to loss data. This approach avoids the limitations typically associated with loss data (spatially sparse, short term) whilst being 'impact-based' in that the metrics are designed to directly relate to the potential for loss should an asset exist in an affected location (e.g. [33]). Our hazard metric for extreme wind is based on regressions against loss data in previous studies, whilst a surrogate measure for flood hazard is proposed based on a calibration to losses conducted within this paper. Both metrics are outlined and justified below.

The seasonally aggregated, impact-based hazard metric used in this study for extreme wind is $H_{W}$, with $H_{W}=\sum\left(v_{\max }-c\right)^{3}$ for $v_{\max }>c$. In this relationship $v_{\max }$ is daily maximum $10 \mathrm{~m}$ gust wind speed, $c$ is a threshold over which damage is thought to occur, and the summation is across a season of data. Whilst a percentile might be used to define the threshold c [34], a value of $20 \mathrm{~ms}^{-1}$ is taken because damage to buildings increases markedly and non-linearly above this $[35,36] . v^{3}$ is used to account for this nonlinearity as total power dissipation in wind storms, the energy available to do damage, rises roughly as $v^{3}$ $[15,33,37,38]$. Thus $H_{W}$, is a well-established hazard metric, taken here as an aggregate over a season, which is designed and calibrated to linearly relate to the potential for wind damage and is thus a proxy for impact. Sensitivity tests for the choice of $c$ are in Supp. Mat. section SM2.

The seasonally aggregated, impact-based hazard metric used in this study for flooding is $H_{R}$, with $H_{R}=\sum R$ where $R$ is total daily precipitation in $\mathrm{mm}$ and the summation is across a season. Aggregated winter precipitation is a common climatic variable, but is proposed as a hazard metric, a surrogate for the hazard of flooding, on a two-fold basis. First, antecedence (e.g. via soil saturation) is important for precipitation-driven hazards including flooding $[11,39,40]$, and so integrating rainfall preceding events into a metric is likely beneficial. Secondly, $H_{R}$ observations in the period 2006-2019 correlate with losses from delays on the rail network of Great Britain (GB), an empirical demonstration that $H_{R}$ has some descriptive power with respect to damage. See Supp. Mat. section SM1 for the analysis underpinning this assertion of correlation $\left(r_{p}^{2}=0.63, p=0.0012\right.$, figure S1 (available online 

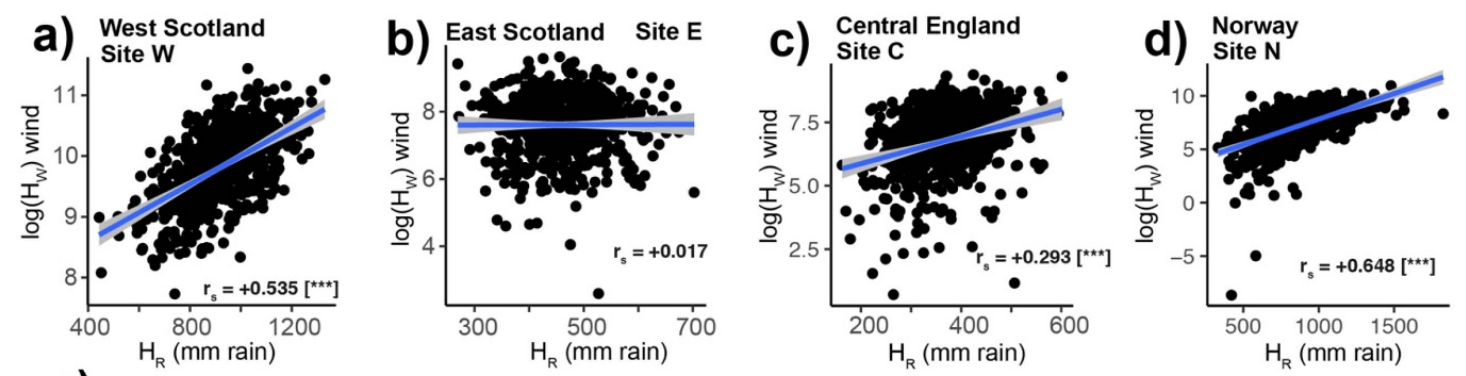

e)
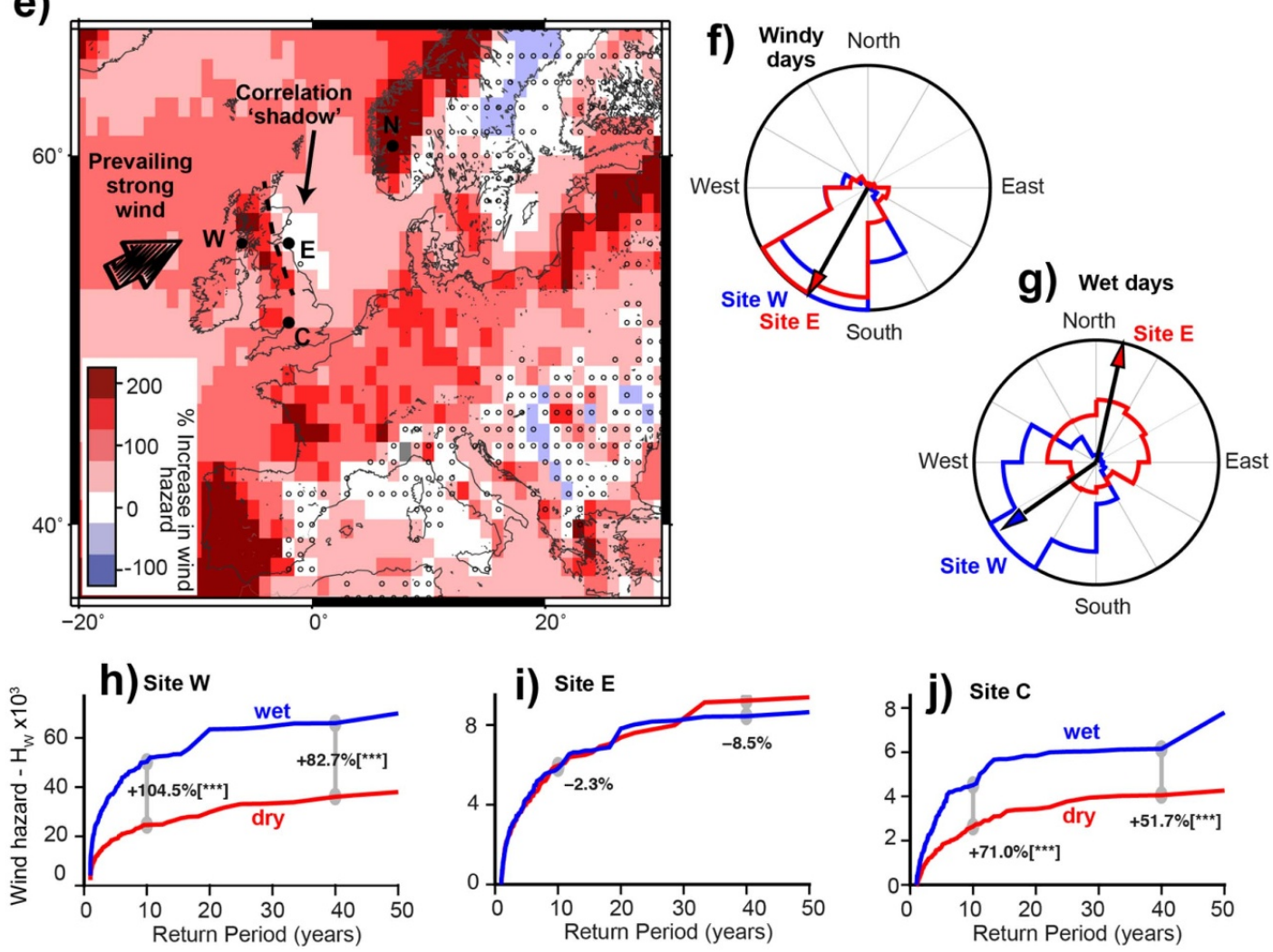

Figure 2. Impact-based estimate of compounding between the hazards of flooding and extreme wind. (a)-(d) Scatter plots of the seasonal hazard metrics $H_{R}$ and $H_{W}$, with ordinary least squares best-fit lines and $3 \sigma$ confidence intervals, at sites W/E/C/N located in panel (e). (e) Map of increase in hazard $(U)$ in wet over dry years, with $f=0.33 . U=100 *\left(H_{w_{-} w e t} / H_{w_{-}}\right.$dry -1$)$. Circles indicate a lack of statistical significance. (f) Orientation of winds on windy ( $>99$ th percentile) days for sites W and E, which is consistent with weather station data [58]. (g) as panel (f) but for wet days. (h)-(j) AEP curves for $H_{W}$, for wet (blue) and dry (red) seasons at the three sites. Differences given at 10 and 40 year return periods. Where statistically significant, $p$ values are in []; ${ }^{*}<0.1,{ }^{* *}<0.05,{ }^{* *}<0.01$. Site locations: $\mathrm{W}\left(-006^{\circ}, 56^{\circ}\right), \mathrm{E}\left(-002^{\circ}, 56^{\circ}\right), \mathrm{C}\left(-002^{\circ}, 52^{\circ}\right), \mathrm{N}\left(001^{\circ}, 61^{\circ}\right)$.

at https://stacks.iop.org/ERL/15/114013/mmedia)), which also contains sensitivity tests for the functional form of $H_{R}$. In the typology of figure 1, therefore, summed precipitation $\left(H_{R}\right)$ is a climate metric, but is also a hazard metric directly related to the potential for damage by flooding. This last property of $H_{R}$ helps in producing outputs of relevance to stakeholders (section 5).

\subsection{Data}

$v_{\text {max }}$ and $R$ data are from SEAS5, the ECMWF Seasonal forecast System 5, re-gridded to $1^{\circ} \times 1^{\circ}$ $[41,42]$. Each member of the SEAS ensemble (versions 4 or 5) is a physically consistent realisation of a potential reality $[43,44]$. SEAS5 hindcasts have 25 members spanning 24 years (1993-2016) considered by ECMWF to be most relevant to the current day in the context of climate change [45]. Simulations run for 7 months, and September re-forecasts are chosen to capture the 'winter' half-year (Oct-Mar) when it is assumed the imprint of initialization conditions will have faded and the ensemble diverged sufficiently [44]. Namely, September itself is excluded to remove 'real' weather. This approach [43, 44, 46-49], as used here, gives 600 simulated years $(24$ years $\times 25$ members) that might plausibly have occurred.

\subsection{Mapping method}

Compounding is mapped (figure 2(e)) by an increase $(U)$ in mean wind hazard $\left(H_{W}\right)$ in the wettest one third as opposed to the driest one third of years; namely, a composite analysis (e.g. $[16,24,50])$ where a fraction $(f=0.333)$ of years are taken as wet. The statistical significance of $U$ is determined by a 
$t$-test. Correlations, Pearson's $\left(r_{p}\right)$ and Spearman's rank $\left(r_{s}\right)$, between $H_{W}$ and $H_{R}$ are examined at selected sites to support this mapping (figures $2(\mathrm{a}-\mathrm{d})$ and S2). To help understand the potential effects of compounding upon impact, exceedance probability (EP) curves are plotted to contrast the wet and dry states (figures $2(\mathrm{~h}-\mathrm{j})$ ). For these conditional probability distributions, the statistical significance of the difference between states at each return period is determined by a stochastic simulation (10000 iterations), which determines if differences from an uncorrelated state exist $[2,51-53]$. The procedure to calculate aggregate exceedance probability (AEP) curves is standard [21], and the use of conditional probability distributions is placed in the context of other widely used approaches in a review by Hao et al [54]. Whilst noting advances in statistical modelling multivariate extremes [6, 53-57], to make implementation of the approach as pragmatic as possible by academics and practitioners, we have selected the simplest sufficient methods.

\section{Results: impact-based map of compounding hazards}

To build upon the existing studies of Great Britain (GB) [2, 4, 11, 29], and previous mapping that used short time windows (24-72 h) [12], impactbased metrics for flooding $\left(H_{R}\right)$ and extreme wind $\left(H_{W}\right)$ are used to map how these hazards compound across Europe on a seasonal timescale (figure 2(e)). In the Atlantic to the north and west of GB, there is an increase of roughly $+100 \%$ in hazard related to extreme wind during wet years (pink). If this is taken as a background level of correlation, similar to Central site C (figure 2(c)), it is modified across the north of GB; compounding is enhanced to the west (Western site W, figure 2(a)) and suppressed to the east (Eastern site E, figure 2(b)). Similar patterns of enhanced-suppressed correlation occur across Scandinavia (Norway/Sweden) and the Iberian Peninsula. Elsewhere, the background level of positive correlation $(\sim 100 \%)$ is present across northwest and central Europe (France, Germany), whilst compounding is low in magnitude and statistically insignificant (white/blue colours, circles) over a broad region in the south and east of Europe (e.g. Italy). This spatial pattern (relative magnitudes) of compounding in figure 2(e) is broadly insensitive to the measure of correlation used in the mapping $\left(U, r_{p}, r_{s}\right)$, threshold $c$ (fixed value or percentile), fraction $f$ of years defined as 'wet' or 'dry', or indeed a shorter Nov-Feb winter (figure S2); see Supp. Mat. section SM2 for detail of the sensitivity tests.

In terms of wider implications, figure 2 demonstrates that using impact-based seasonal hazard metrics is a pragmatic means of mapping compounding hazards; the data are global and readily available, the metrics are easy to compute, and statistical tests basic. In detail, we acknowledge that local (sub-grid) associations and variations are not captured, perhaps on exposed hilltops outside mountainous areas (e.g. SW England) or between neighbouring valleys [59], and that some mechanisms for flooding such as snow melt (e.g. [40]) are not accounted for.

\section{Discussion: enhanced compounding and correlation shadows}

Figure 2(e) presents a view of the potential for the hazards of flooding and extreme wind to combine at seasonal timescales. There are both similarities to, and differences from, the only such prior mapping work, which considered co-occurrence within short ( $\leq 72 \mathrm{~h}$ ) timeframes [12]. The areas of strongest short-term correlation were in North and Baltic Seas [12]. These are muted in figure 2(e), leaving paired areas of enhanced-supressed risk more distinct (Norway, Iberia, GB, South Sweden, South Italy). Given that the data used in the two studies were similar (ECMWF, $1^{\circ} \times 1^{\circ}$ ), why are certain patterns evident with increased clarity in figure 2? Statistical simulation modelling (detailed in Supp. Mat. section SM5) provides an explanation (figure 3 ). At sites in figure 2 where compounding is significant $(\mathrm{W} / \mathrm{C} / \mathrm{N})$, figure 3 shows that the majority $(\sim 70 \%-90 \%)$ of the compounding effect upon combined hazard is plausibly attributable to a relationship between the hazards at timescales over $72 \mathrm{~h}$. Thus, without being in conflict with observations that flooding and wind hazards combine within individual storms [12, 24-28], figures 2 and 3 support the proposal [2, 4, 11, 29] that persistent underlying environmental conditions might enhance compounding of the flood-wind hazard by acting across multiple storms. A striking difference between figure 2(e) and mapping of short-term correlation [12] is in the region of GB. We therefore choose this area to investigate the patterns and mechanisms at work in more depth and detail, firstly where correlation is enhanced in the north-west, and then where it is suppressed in the north-east.

Flooding and wind hazard metrics in Great Britain compound most strongly in the north, to the west of the hills that run northwards from the Pennines into the Scottish Highlands (figure 2(e)). Storms and strong winds predominantly hit GB from the south-west (figure 2(f)) [14, 24, 58]. In these lowpressure frontal systems, the heaviest topographically enhanced rainfall occurs in the warm sector of the depressions in association with strong winds there [60-62]. This orographic enhancement over moderate amplitude topography is widely thought to be caused by the seeder-feeder mechanism [62-64], and the resulting rainfall is the main driver of flooding in affected areas (e.g. [65-67]). In SEAS5, these behaviours are evident in the agreement of wind directions for the windiest and wettest days at Site W (figures $2(\mathrm{f}-\mathrm{g})$, blue), and in the 

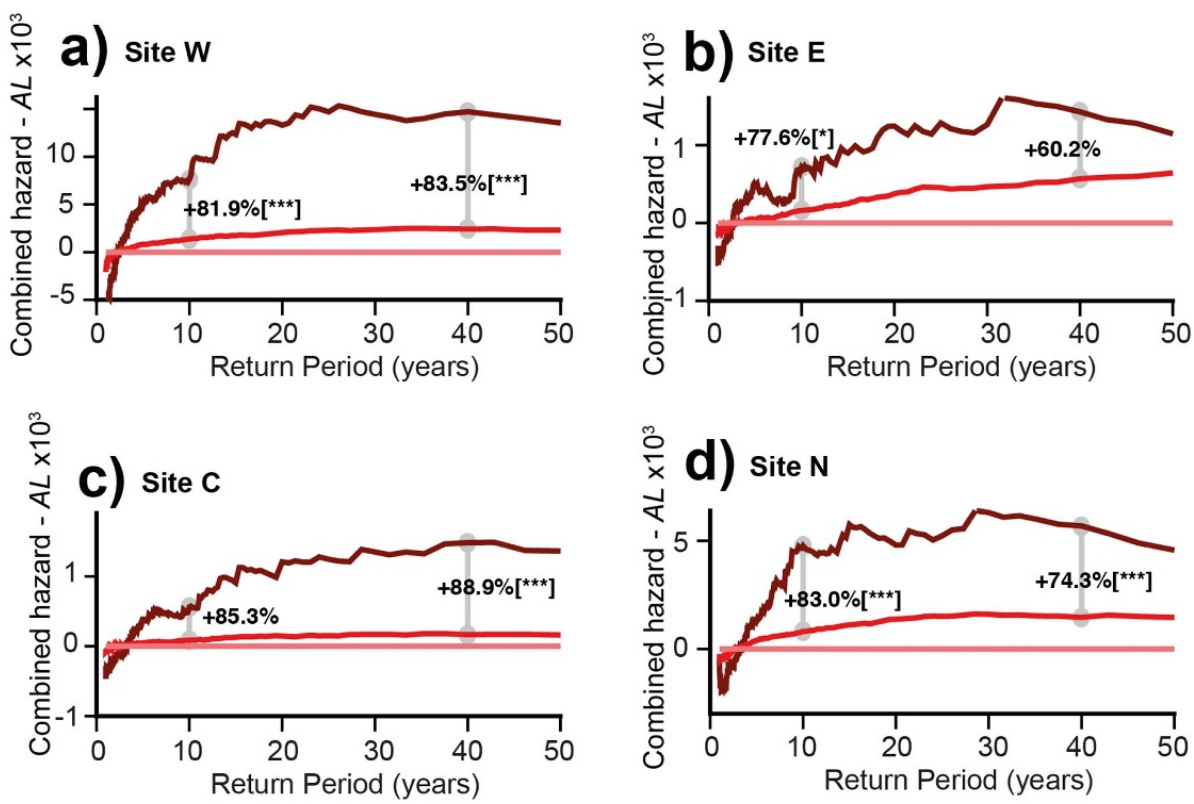

Figure 3. Breakdown of timescales contributing to compounding at the four sites. All panels are Aggregate Exceedance Probability (AEP) plots. $A L$ is an estimate of combined hazard for flooding and extreme wind. $A L$ is displayed as a difference from a simulated condition of independence between the hazards (pink line, condition C). Data directly from SEAS5 (dark red, condition A) plot above a condition in which associations between extremes within a $72 \mathrm{~h}$ window are retained but any longer-term relationships (e.g. monthly) are removed (red, condition B). Numerical differences between conditions A and B, due to longer term (from $72 \mathrm{~h}$ up to seasonal) effects, are shown at 10 and 40 years return periods (vertical grey lines). Where statistically significant, $p$ values are in []; ${ }^{*}<0.1,{ }^{* *}<0.05,{ }^{* *}<0.01$. Total (and average) of $A L$ is identical in all 3 conditions, merely re-distributed.

high correlation between wind and rain $\left(v_{\max }\right.$ and $R$ ) at site $\mathrm{W}$ both in daily data (Supp. Mat. section SM3, $\left.r_{s}=0.607, p<0.01\right)$ and the seasonal hazard metrics (figure 2(a)). So, the enhancement of joint flood and wind hazard in the north-west of GB is compatible with a well-established understanding of physical processes acting there. Furthermore, the expected behaviours are evident in the SEAS5 data, suggesting that it is appropriate to interpret other patterns that emerge from the SEAS5 data. Thus, the existing understanding is demonstrably not a complete explanation because the very windiest days at site $\mathrm{W}$ are wet but not the wettest ones (figure S3); see Supp. Mat. section SM3 for details. Namely, storms impacting site $\mathrm{W}$ either tend to be wet or windy, not extreme in both. Why? We suggest that this is because storms with the most damaging winds are likely to still be actively interacting with the jet stream, but those with the most extreme rain are probably not. Such interaction is known to intensify storms, increasing $v_{\max }$ and wind damage potential, whilst simultaneously causing them to travel rapidly $[68,69]$. This would allow storms with the most intense winds less time than slower-moving systems to rain at any given site on the ground. The translational speed of extratropical storms impacting Europe adds only a minor amount to $v_{\max }[21,70]$, so this is probably not a major factor. This conceptual model is based on an established physical mechanism, and is an explanation for why persistence (i.e. $>72 \mathrm{~h}$ ) appears to play a role in creating the enhanced correlations in figures 2 and 3. It is not possible yet, however, to fully answer the question posed at the start of this paper and say whether the correlation mainly arises from the clustering of storms within the relatively short time windows $(\lesssim 14$ days) that create widespread flooding $[11,23,71]$ or from persistence on climatological timescales (up to months) to create wet and stormy winters $[4,29,32,72-74]$.

East of the hills, correlation is suppressed, to which we give the label 'correlation shadow' (figures 2(b) and (e)). As a potential contributor to such features Martius et al [12] invoked the Föhn effect to generate a rain shadow, but did not discuss detail or physical mechanisms [75-78]. Most simply, the decorrelation arises because winds bearing the most intense rain to site $\mathrm{E}$ (northerly) come from a different direction to the strongest winds, which are from the south-west and not the north (figures $2(\mathrm{f}-\mathrm{g})$, Supp. Mat. SM3). Why does this arise? Daily $v_{\max }$ values show that the strength of the severest gusts within a $24 \mathrm{~h}$ window at sites $\mathrm{E}$ and $\mathrm{W}$ is strongly related $\left(r_{s}=0.773, p<0.01\right)$, indicating that both typically arise from the same weather patterns, but extreme rain does not commonly follow at site E $\left(r_{s}=0.069\right)$; see Supp. Mat. section SM3 for details. So, the key to understanding figure 2(e) is the difference in site-specific response to a similar set (figure S4) of impacting weather patterns or air masses. The concept of a rain-shadow $[12,75,76]$ cannot be as readily invoked in GB as 
it is for larger mountains [77, 79]. However, the strongest rain-shadow effect in the type of low pressure frontal systems that impact GB occurs for precipitation in their warm sector of $[62,77,80,81]$, which is exactly the situation driving the compounding effect at site $\mathrm{W}$ (see above). That is, it is possible to propose that enhanced orographic precipitation on the windward western side of the topography partially dries the air mass, reducing rainfall in the lee. Thus, the correlation shadow can be partially understood as a consequence of the seeder-feeder mechanism [62], potentially reinforced by tendencies towards mutual exclusivity between wind directions within a season. At a seasonal level, the wind directions (weather types) related to flood hazard and extreme wind at site E are known to trade-off with each other [82-84]. In particular, when westerly winds are common those from the north and east occur less frequently (figure S5). This effect might in theory induce inverse relationships [4], but does not appear to be strong enough to do so as none of the negative correlations in the mapping are statistically significant (figures 2(e) and (i)).

In summary, this example involving the hazards of flooding and extreme wind in GB highlights that using seasonal impact-based hazard metrics can identify phenomena to investigate further (e.g. with daily data) and poses questions to drive future research. How does the mechanism driving GB's correlation shadow compare to that of Scandinavia or the western USA? How prevalent is each type of extra-tropical correlation shadow globally? How strong is compounding in the most extreme seasons and rarest events? How will these change in future?

\section{Impact of compounding effects}

Many stakeholders, such as the (re)insurance sector or a rail network provider, need to understand rare and extreme years for the purposes of planning. Will the compound aggregate loss in a season likely exceed their limits permitted by regulation, repair capacity or financial reserves? A correlation driven by moderately extreme but frequent environmental conditions is likely not a concern, whereas a dependency that exhibits itself as both very severe flooding and wind damage in the same year would be. In this context, securely establishing $(p<0.05)$ that wind hazard $\left(H_{W}\right)$ is elevated in wet years out to return periods up to $\sim 50$ years (figures $2(\mathrm{~h})$ and $(\mathrm{j})$ ) is an important result for GB. With wet years explicitly linked (calibrated) to increased flooding impacts (figure S1), and strong evidence that $H_{W}$ reflects wind damage (section2.1), this lends weight to the idea that the flood-wind correlation identified for both hazard and risk from relatively short time series in previous studies $[2,4,11,12,29]$ is also present at higher return periods. This inference about rarer, more extreme co-occurrences is only possible as the hazard proxies $\left(H_{R}, H_{W}\right)$ draw upon 600 years of SEAS5 data, and is lent significant additional weight in terms of practical interpretation as both hazard metrics are impactbased in that they have been calibrated to the observed impacts (section 2.1). As such, results from the analysis of hazard are indicative of the potential for damage in both the AEP curves (figures $2(h-j)$ ) and the mapping (figure 2(e)). In short, the use of seasonal, impact-based hazard metrics has allowed us to build additional understanding of real-world relevance over and above that possible from the relatively short observational record.

\section{Conclusions}

By applying seasonal, impact-based hazard proxies to map how flooding and extreme wind compound across Europe, using SEAS5 data, our view is that such mapping is useful for three main reasons:

1. It is a pragmatic, self-consistent (i.e. using similar data) means to map compounding hazards across large regions using publicly available data (e.g. SEAS5). This said, where possible we advocate site-specific studies using alternative data (e.g. river flows, weather station data) and higher resolutions (spatial and temporal) to validate the observations and gain deeper process-based understanding (e.g. [85]).

2. The mapping identifies phenomena (e.g. correlation shadows) to drive the research agenda, posing questions and generating hypotheses about atmospheric behaviour for future investigation and testing.

3. The outputs (e.g. \% increase in losses, AEP curves) are seasonal, at a time-scale relevant to many stakeholder's resource planning horizons, and thus of direct real-world relevance.

This approach could readily be applied to different regions, or to diverse and potentially timelagged hazard combinations (e.g. landslide, snow, heat, wind).

\section{Acknowledgments}

We thank Rob Wilby and Alex Alabaster for their comments on early drafts of this manuscript, and two anonymous reviewers for their constructive critique of the submitted version. Both of these improved the paper. Hillier is funded by the UKRI, NERC KE Fellowship NE/R003297/1.

\section{Data availability statement}

The data that support the findings of this study are openly available at the following URL/DOI: https://cds.climate.copernicus.eu/\#!/home. 


\section{Author contributions}

Dixon conceived the work. Hillier and Dixon together devised and conducted the analyses, reviewed existing literature, discussed the results and wrote the paper.

\section{References}

[1] Kappes M S, Keiler M, von Elverfeldt K and Glade T 2012 Challenges of analyzing mulit-hazard risk: a review Nat. Hazards 64 1925-58

[2] Hillier J K, Macdonald N, Leckebusch G C and Stavrinides A 2015 Interactions between apparently primary weather-driven hazards and their cost Environ. Res. Lett. 10104003

[3] de Ruiter M, Couasnon A, van den Homberg M J C, Daniell J E, Gill J and Ward P J 2020 Why we can no longer ignore consecutive disasters Earth's Future 8 e2019EF001425

[4] Hillier J K, Matthews T, Wilby R L and Murphy C 2020 Multi-hazard dependencies can increase and decrease risk Nat. Clim. Change $10595-8$

[5] Zscheischler J et al 2018 Future climate risk from compound events Nat. Clim. Change 8 469-77

[6] Bevacqua E, Maraun D, Haff H I, Widmann M and Vrac M 2017 Multivariate statistical modelling of compound events via pair-copula constructions: analysis of floods in Ravenna (Italy) Hydrol. Earth Syst. Sci. 21 2701-23

[7] Moftakhari H, Schubert J E, AghaKouchak A, Matthew R A and Sanders B F 2019 Linking statistical and hydrodynamic modeling for compound flood hazard assessment in tidal channels and estuaries Adv. Water Resour. 128 28-38

[8] Khouakhi A and Villarini G 2017 Contribution of tropical cyclones to rainfall at global scale J. Clim. 30 359-72

[9] Matthews T, Wilby R L and Murphy C 2019 An emerging tropical cyclone-deadly heat compound hazard Nat. Clim. Change 9 602-6

[10] Ward P J, Couasnon A, Eilander D, Haigh I D, Hendry A, Muis S, Veldkamp T I E, Winsemius H C and Wahl T 2018 Dependence between high sea-level and high river discharge increases flood hazard in global deltas and estuaries Environ. Res. Lett. 13084012

[11] De Luca P, Hillier J K, Wilby R L, Quinn N W and Harrigan S 2017 Extreme multi-basin flooding linked with extra-tropical cyclones Environ. Res. Lett. 12114009

[12] Martius O, Pfahl S and Chevalier C 2016 A global quantification of compound precipitation and wind extremes: compound precipitation and wind extremes Geophys. Res. Lett. 43 7709-14

[13] Steptoe H, Jones S E O and Fox H 2018 Correlations between extreme atmospheric hazards and global teleconnections: implications for multi-hazard resilience Revi. Geophys. $5650-78$

[14] Walz M A, Donat M G and Leckebusch G C 2018 Large-scale drivers and seasonal predictability of extreme wind speeds over the North Atlantic and Europe J. Geophys. Res.: Atmos. $12311518-35$

[15] Chan J C L 2007 Interannual variations of intense typhoon activity Tellus A 59 455-60

[16] Camargo S J and Sobel A H 2010 Western North Pacific tropical cyclone intensity and ENSO J. Clim. 23 5810-25

[17] Mariani M, Fletcher M S, Holz A and Nyman P 2016 ENSO controls interannual fire activity in southeast Australia Geophys. Res. Lett. 43 10891-900

[18] Bieli M, Pfahl S and Wernli H A 2015 Lagrangian investigation of hot and cold temperature extremes in Europe Q. J. R. Meteorol. Soc. 141 98-108

[19] West H, Quinn N and Horswell M 2019 Regional rainfal response to the North Atlantic oscillation (NAO) across Great Britain Hydrol. Res. 50 1549-63

[20] Zscheischler J and Seneviratne S I 2017 Dependence of drivers affects risks associated with compound events Sci. Adv. 3 e1700263
[21] Mitchell-Wallace K, Jones M, Hillier J K and Foote M 2017 Natural Catastrophe Risk Management and Modelling: A Practitioner's Guide (Wiley: Oxford, UK) pp 506

[22] Donat M G, Leckebusch G C, Wild S and Ulbrich U 2011 Future changes in European winter storm losses and extreme wind speeds inferred from GCM and RCM multi-model simulations Nat. Hazards Earth Syst. Sci. 11 1351-70

[23] Lavers D A, Allan R P, Villarini G, Lloyd-Hughes B, Brayshaw D J and Wade A J 2013 Future changes in atmospheric rivers and their implications for winter flooding in Britain Environ. Res. Lett. 8034010

[24] Matthews T, Murphy C, McCarthy G, Broderik C and Wilby R L 2018 Super Storm Desmond: a process-based assessment Environ. Res. Lett. 13014024

[25] Otto F, van der Wiel K and van Oldenborgh G J 2018 Climate change increases the probability of heavy rains in Northern England/Southern Scotland like those of storm Desmond-a real-time event attribution revisited Environ. Res. Lett. 13024006

[26] Fink A H, Brucher T, Ermert V, Kruger A and Pinto J G 2009 The European storm Kyrill in January 2007: synoptic evolution, meteorological impacts and some considerations with respect to climate change Nat. Hazards Earth Syst. Sci. 9 405-23

[27] Raveh-Rubin 2015 Large-scale wind and precipitation extremes in the Mediterranean: a climatological analysis for 1979-2012 Q. J. R. Meteorol. Soc. 141 2404-17

[28] Liberato M L R 2014 The 19 January 2013 windstorm over the North Atlantic: large-scale dynamics and impacts on Iberia Weather Clim. Extremes 5-6 16-28

[29] Matthews T, Murphy C, Wilby R L and Harrigan S 2014 Stormiest winter on record for Ireland and UK Nat. Clim. Change 4 738-40

[30] De Luca P, Messori G, Pons F M E and Faranda D 2020 Dynamical systems theory sheds new light on compound climate extremes in Europe and Eastern North America Q. J. R. Meteorol. Soc. 146 1636-50

[31] Zscheischler J et al $2014 \mathrm{~A}$ few extreme events dominate global interannual variability in gross primary production Environ. Res. Lett. 9035001

[32] Palin E J, Scaife A A, Wallace E, Pope E, Arribas A and Brookshaw A 2016 Skillful seasonal forecasts of winter disruption to the U.K. transport system J. Appl. Meteorol. Climatol. 55 325-44

[33] Emanuel K 2005 Increasing destructiveness of tropical cyclones overthe past 30 years Nature 436 686-8

[34] Klawa M and Ulbrich U 2003 A model for the estimation of storm losses and the identification of severe winter storms in Germany Nat. Hazards Earth Syst. Sci. 3 725-32

[35] Geiger T, Frieler K and Bresch D 2013 A global historical data set of tropical cyclone exposure (TCE-DAT) Earth Syst. Sci. Data 10 185-94

[36] Hawker M 2007 Climate change and the global insurance industry Geneva Pap. 32 22-8

[37] Nordhaus W 2010 The economics of hurricanes and implications of global warming Clim. Change Econ. 1 1-20

[38] Southern R L 1979 The global socio-economic impact of tropical cyclones Aust. Meteorol. Mag. 27 175-95

[39] Postance B, Hillier J K, Dijkstra T and Dixon N 2017 Comparing threshold definition techniques for rainfall-induced landslides: a national assessment using radar rainfall Earth Surf. Process. Landf. 43 553-60

[40] Berghuijs W R, Harrigan S, Molnar P, Slater L and Kirchner J W 2019 The relative importance of different flood-generating mechanisms across Europe Water Resour. Res. 55 4582-93

[41] Johnson S J et al 2019 SEAS5: the new ECMWF seasonal forecast system Geosci. Model Dev. 12 1087-117

[42] CDS 2020 'CDS Home Page' https://cds.climate.copernicus. $\mathrm{eu} / \# ! /$ home (Accessed April 30, 2020)

[43] Osinski R, Lorenz P, Kruschke T, Voigt M, Ulbrich U, Leckebusch G C, Faust E, Hofherr T and Majewski D 2016 An approach to build an event set of European wind storms 
based on ECMWF EPS Nat. Hazards Earth Syst. Sci. Discuss. $16255-68$

[44] Walz M A and Leckebusch G C 2019 Loss potentials based on an ensemble forecast: how likely are winter windstorm losses similar to 1990? Atmos. Sci. Lett.

[45] Stockdale T, Johnson S, Ferranti L, Balmaseda M and Briceag S 2018 'ECMWF's new long-range forecasting system SEAS5’ ECMWF Newsletter p 154 https://www.ecmwf. int/en/newsletter/154/meteorology/ecmwfs-new-longrange-forecasting-system-seas5 (Accessed February 12, 2020)

[46] van den Brink H W, Können G P, Opsteegh J D, van Oldenborgh G J and Burgers G 2004 Improving 104-year surge level estimates using data of the ECMWF seasonal prediction system Geophys. Res. Lett. 31 L17210

[47] Breivik Ø, Aarnes O J, Abadalla S, Bidlot J-R and Janssen P 2014 Wind and wave extremes over the world oceans from very large ensembles Geophys. Res. Lett. 41 5122-31

[48] Thompson V, Dunstone N J, Scaife A A, Smith D M, Slingo J M, Brown S and Belcher S E 2017 High risk of unprecedented UK rainfall in the current climate Nat. Commun. 8107

[49] Kelder T et al'UNSEEN trends: detecting decadal changes in 100-year precipitation extremes' In Prep https://eartharxiv.org/hyxeq/

[50] Boucharel J, Jin -F-F, Lin I I, Huang H-O and England M 2016 Different controls of tropical cyclone acitivity in the Eastern Pacific for two types of El Niño Geophys. Res. Lett. 43 1679-86

[51] Muir-Wood R, Drayton M, Berger A, Burgess P and and Wright T 2005 Catastrophe loss modelling of storm-surge flood risk in eastern England Phil. Trans. R. Soc A 363 1407-22

[52] Lamb R, Keef C, Tawn J, Laeger S, Meadowcroft I, , Surendran S, Dunning P and Batstone C 2010 A new method to assess the risk of local and widespread flooding on rivers and coasts J. Flood Risk Manag. 3 323-36

[53] Wyncoll D and Gouldby B 2013 Integrating a multivariate extreme value method within a system flood risk analysis $J$. Flood Risk Manag. 8 145-60

[54] Hao Z, Singh V P and Hao F 2018 Compound extremes in hydroclimatology: a review Water 10 art.no. 718

[55] Serinaldi F and Papalexiou S M 2020 Random fields simplified: preserving marginal distributions, correlations, and intermittency, with applications from rainfall to humidity Water Resour. Res. 56 e2019WR026331

[56] Wadsworth J L, Tawn J A, Davidson A C and Elton D M 2017 Modelling across extremal dependence classes J. R. Stat. Soc. B 79 149-75

[57] Hao Z, Hao F, Singh V P, Xia Y, Shi C and Zhang X 2018 a multivariate approach for statistical assessments of compound extremes J. Hydrol. 565 87-94

[58] Hewston R and Dorling S R 2011 An analysis of observed daily maximum wind gusts in the UK J. Wind Eng. Ind. Aerodyn. 99 845-56

[59] Malby A R, Whyatt J D, Timmis R J, Wilby R L and Orr H G 2007 Long-term variations in orographic rainfall: analysis and implications for upland catchments Hydrol. Sci. 52 276-91

[60] Douglas C K M and Glasspoole J 1947 Meteorological conditions in heavy orographic rainfall Q. J. R. Meteorol. Soc. $7311-38$

[61] Hill F F, Browning K A and Bader M J 1981 Radar and rain gauge observations of orographic rain over South Wales 107 643-70

[62] Smith S A, Vosper S B and Field P R 2015 Sensitivity of orographic precipitation enhancement to horizontal resolution in the operational Met Office Weather forecasts Meteorol. Appl. 22 14-24

[63] Bergeron T 1965 On the low-level redistribution of atmospheric water caused by orography Supplementary Proc. of the Int Conf. on Cloud Physics (Tokyo, Japan: IAMAP/WMO) pp 96-100

[64] Dore A J, Choularton T W, Brown R and Blackall R M 1992 Orographic rainfall enhancement in the mountains of the Lake District and Snowdonia Atmos. Environ. 26A 357-71

[65] Sibley A, Cox D and Titley H 2015 Coastal flooding in England and Wales from Atlantic and North Sea storms during the 2013/2014 winter Weather 70 62-70

[66] Eden P and Burt S 2010 Extreme rainfall in Cumbria, 18-20 November 2009 Weather 6514

[67] Roberts N M, Cole S J, Forbes R M, Moore R J and Boswell D 2009 Use of high-resolution NWP rainfall and river flow forecasts for advance warning of the Carlisle flood, north-west England Meteorol. Appl. 16 23-34

[68] Geng Q and Sugi M 2001 Variability of the North Atlantic cyclone activity in winter analyzed from NCEP-NCAR reanalysis data J. Clim. 14 3863-73

[69] Ulbrich U, Leckebusch G C and Pinto J G 2009 Extra-tropical cyclones in the present and future climate: a review Theor. Appl. Climatol. 96 117-31

[70] Loridan T, Scherer E, Dixon M, Bellone E and Khare S 2014 Cyclone wind field asymmetries during extratropical transition in the Western North Pacific J. Appl. Meteorol. Climatol. 53 421-8

[71] Vitolo R, Stephenson D S, Cook I and Mitchell-Wallace K 2009 Serial clustering of intense European storms Meteorol. Z. 18 411-24

[72] Kendon M and McCarthy M 2015 The UK's wet and stormy winter of 2013/2014 Weather 7 40-47

[73] Huntingford C, Marsh T, Scaife A A and Kendon E J 2014 Potential influences on the United Kingdom's floods of winter 2013/14 Nat. Clim. Change 4 769-77

[74] Wild S, Befort D J and Leckebusch G C 2015 Was the extreme storm season 2013-14 over the North Atlantic and the UK triggered by changes in the West-Pacific Warm Pool? Bull. Am. Meteorol. Soc. 96 S29-34

[75] Smith R B 1979 The influence of mountains on the atmosphere Adv. Geophys. 21 87-230

[76] Sinclair M R 1994 A diagnostic model for estimating orographic precipitation J. Appl. Meteorol. 33 1163-75

[77] Stockham A J, Schultz D M, Fairman J G and Draude A P 2018 Quantifying the rain-shadow effect: results from the Peak District, British Isles Bull. Am. Meteorol. Soc. 99 777-90

[78] Elvidge A D 2015 The causes of foehn warming in the lee of mountains Bull. Am. Meteorol. Soc. 97 455-66

[79] Rosenberg N J 1986 Climate of the great plains region of the United States Great Plains Q. 7 22-32 www.jstor.org/stable/23530686

[80] Silner N, Roe G and Durran D 2013 On the dynamical causes of variability in the rain-shadow effect: a case study of the Washington Cascades J. Hydrometeorol. 14 122-39

[81] Mass C, Johnson N, Warner N and Vargas R 2015 Synoptic control of cross-barrier precipitation ratios for the Cascade Mountains J. Hydrometeorol. 16 1014-28

[82] Briffa K R, Jones P D and Kelly P M 1990 Principal component analysis of the Lamb catalogue of daily weather types: part 2, seasonal frequencies and update to 1987 Int. J. Climatol. 10 549-63

[83] Jones P D, Osborn T J, Harpham C and Briffa K R 2014 The development of Lamb weather types: from subjective analysis of weather charts to objective approaches using reanalyses Weather 69 128-32

[84] Wilby R L and Quinn N W 2013 Reconstructing multi-decadal variations in fluvial flood risk using atmospheric circulation patterns J. Hydrol. 487 109-21

[85] Halliday O, Shafferty L, Tsaknias D, Siddaway A and Cloke H 'Understanding the Risk from Correlated Windstorms and Floods in the UK' (in preparation) https://presentations. copernicus.org/EGU2020/EGU2020-20230_presentation.pdf 